\title{
新型席夫碱 $\mathrm{Cr}^{3+}$ 苂光探针及其细胞成像研究
}

\author{
常永新 $a$ 李 白 ${ }^{a}$ 高云帆 ${ }^{b}$ 徐括喜*,a,b \\ ( ${ }^{a}$ 河南大学化学化工学院 功能有机分子研究中心 河南省阻燃与功能材料工程实验室 开封 475004) \\ ( ${ }^{b}$ 河南大学民生学院 开封 475004)
}

\begin{abstract}
摘要 $\mathrm{Cr}^{3+}$ 离子在脂肪、核酸、糖和蛋白质的代谢中发挥着重要作用, 并且 $\mathrm{Cr}^{3+}$ 离子被认为是一种致癌物质, 对人类有 极大的危害. 因此, 通过将 8-差基哇啉醛和硫代碳酰肼反应制备出化合物 $\mathbf{L}$. 探针 $\mathbf{L}$ 的 $\mathrm{CH}_{3} \mathrm{CN} / \mathrm{H}_{2} \mathrm{O}(V: V=1: 2$, Tris buffer $50 \mathrm{mmol} / \mathrm{L}, \mathrm{pH}=7.3$ ) 溶液中加入 $\mathrm{Cr}^{3+}$ 离子, 可以通过肉眼观察到其颜色从无色到黄色的变化和明显的苂光增强 效应, 这些现象表现出探针 $\mathbf{L}$ 对 $\mathrm{Cr}^{3+}$ 离子具有良好的选择性. 根据 Job 曲线、苂光滴定、质谱和密度泛函理论(DFT) 计算确定了探针 $\mathbf{L}$ 与 $\mathrm{Cr}^{3+}$ 离子形成 $1: 1$ 的络合物. 络合常数为 $1.00 \times 10^{5} \mathrm{~L} / \mathrm{mol}$, 检测限为 $2.85 \times 10^{-7} \mathrm{~mol} / \mathrm{L}$. 此外, 生 物成像实验表明, 探针 $\mathbf{L}$ 可以通过荧光增强信号检测活细胞中的 $\mathrm{Cr}^{3+}$ 离子.
\end{abstract}

关键词 $\mathrm{Cr}^{3+}$; 荧光探针; DFT; 细胞成像

\section{A Novel Schiff-Base Fluorescent Probe for $\mathrm{Cr}^{3+}$ and Its Bioimaging in Cells}

\author{
Chang, Yongxin ${ }^{a}$ \\ $\mathrm{Li}, \mathrm{Bai}^{a}$ \\ Gao, Yunfan ${ }^{a}$ \\ $\mathrm{Xu}, \mathrm{Kuoxi}^{*, a, b}$ \\ ( ${ }^{a}$ Institute of Functional Organic Molecular Engineering, Engineering Laboratory for Flame Retardant and Functional \\ Materials of Henan Province, College of Chemistry and Chemical Engineering, Henan University, Kaifeng, 475004) \\ ( ${ }^{b}$ Henan University Mingsheng College, Kaifeng, 475004)
}

\begin{abstract}
Trivalent chromium $\left(\mathrm{Cr}^{3+}\right)$ plays an important role in the metabolismof fats, nucleic acids, carbohydrates and proteins. Moreover, $\mathrm{Cr}^{3+}$ is considered to be a carcinogen and is extremely harmful to humans. Therefore, $\mathrm{Cr}^{3+}$ fluorescent $^{3+}$ probe $\mathbf{L}$ was synthesized by reaction of 8-hydroxyquinolinaldehyde with thiocarbazone. The probe $\mathbf{L}$ showed high selectivity towards $\mathrm{Cr}^{3+}$ ion through the color of solution changed from colorless to yellow for naked-eye detection and significant fluorescence intensity enhanced in $\mathrm{CH}_{3} \mathrm{CN} / \mathrm{H}_{2} \mathrm{O}(V: V=1: 2$, Tris buffer $50 \mathrm{mmol} / \mathrm{L}, \mathrm{pH}=7.3)$ solution. The $1: 1$ binding stoichiometry between probe and $\mathrm{Cr}^{3+}$ was determined from Job's plot, fluorescence titration, ESI-MS and density functional theory (DFT) calculations. The association constant $\left(K_{\mathrm{a}}\right)$ and the detection limit for $\mathrm{Cr}^{3+}$ were found to be to be $1.00 \times 10^{5}$ and $2.85 \times 10^{-7} \mathrm{~mol} / \mathrm{L}$, respectively. Moreover, bioimaging experiments showed that $\mathbf{L}$ could sense $\mathrm{Cr}^{3+}$ ion in living cells with a fluorescence enhancement signal.
\end{abstract}

Keywords $\mathrm{Cr}^{3+}$; fluorescent probe; DFT; bioimaging

三价铬 $\left(\mathrm{Cr}^{3+}\right)$ 是人体中重要的微量元素, 一般情况 下由人类和自然资源释放到环境中的过渡金属通过食 物链在人体中积累. 其中, $\mathrm{Cr}^{3+}$ 离子对维持有效的碳水 化合物、脂质和蛋白质的代谢起着重要的作用. 然而, $\mathrm{Cr}^{3+}$ 离子却被认为是一种致癌物质, 对人类的健康具有 极大的危害 ${ }^{[3]}$. 世界卫生组织(WHO)规定饮用水中 $\mathrm{Cr}^{3+}$ 离子的最大浓度为 $50 \mu \mathrm{g} / \mathrm{L}$, 正常人每天需要吸收 $25 \sim$ $35 \mu \mathrm{g}$ 的 $\mathrm{Cr}^{3+}$ 离子以改善葡萄糖和脂肪的代谢. 人体内
$\mathrm{Cr}^{3+}$ 离子含量的增加会导致患心血管疾病和糖尿病的 风险，而过量摄入 $\mathrm{Cr}^{3+}$ 离子也会对细胞的结构产生不良 影响 ${ }^{[9]}$. 此外, 由于近些年各种工业和农业活动的大规 模增加, $\mathrm{Cr}^{3+}$ 离子已经成为了一种主要的污染物, 其主 要存在于 $\mathrm{CrO}_{4}^{2-}$ 和 $\mathrm{Cr}_{2} \mathrm{O}_{7}^{2-}$ 中并且最终被还原为 $\mathrm{Cr}^{3+}$ 离 子 ${ }^{[10]}$. 目前, 测定 $\mathrm{Cr}^{3+}$ 离子的常用方法包括分光光度 法、电化学方法、原子吸收光谱法(AAS)、电感耦合等 离子体原子发射光谱法(ICP-MS $)^{[18]}$. 虽然 AAS 和

* Corresponding author. E-mail: xukx@henu.edu.cn

Received September 21, 2018; revised October 29, 2018; published online December 7, 2018.

Project supported by the National Natural Science Foundation of China (No. U1404207).

国家自然科学基金(No. U1404207)资助项目. 
ICP-MS 快速准确, 但其价格昂贵. 电化学传感器一般 需要经过长时间的准备, 并且频繁校准, 不适合长期操 作. 分光光度法通常检测极限都比较差. 而苂光测定法 由于其具有合成简单、高灵敏度和即时响应等众多优点 而引起了众多科研工作者的广泛关注. 近些年来探索新 型苂光探针的合成与检测重金属离子和过渡金属离子 已经在超分子化学、有机化学、药物输送、生物化学和 环境化学等研究领域展现其诱人的前景 ${ }^{[20]}$. 因此, 用苂 光测定法检测环境和生物样品中的 $\mathrm{Cr}^{3+}$ 离子显得至关 重要. 但是, 目前很少有关于 $\mathrm{Cr}^{3+}$ 离子苂光检测的报道. 这可能是由于 $\mathrm{Cr}^{3+}$ 离子的顺磁性特征和检测环境的复 杂性, 使得大部分苂光探针是苂光猝灭型的, 而在实际 样品和细胞中增强型探针普遍具有更加优良的性能. 因 此, 开发荧光增强型探针成为一项具有挑战性的任务. 目前, 有多种电子跃迁机制用于开发新型荧光增强型探 针, 例如螯合增强荧光 $(\mathrm{CHEF})$ 、苂光共振能量转移 (FRET)、光诱导电子转移(PET)、光诱导质子转移(PPT)、 激发态分子间质子转移(ESIPT)、分子间电荷转移(ICT)、 $\mathrm{C}=\mathrm{N}$ 异构化等 ${ }^{[21]}$. 在所提到的机制中, 基于 ICT 机制 的探针已被广泛应用. 于是, 我们设计了一种以 8 -差弪基 喹啉醛与硫代碳酰肼缩合得到的新型苂光探针 (图 1). 加入 $\mathrm{Cr}^{3+}$ 离子后, 探针 $\mathbf{L}$ 显示出肉眼可见的颜色变化和 显著的苂光增强, 并且一些常见金属离子包括 $\mathrm{Na}^{+}, \mathrm{K}^{+}$, $\mathrm{Ba}^{2+}, \mathrm{Hg}^{2+}, \mathrm{Co}^{2+}, \mathrm{Cu}^{2+}, \mathrm{Zn}^{2+}, \mathrm{Cd}^{2+}, \mathrm{Fe}^{3+}$ 和 $\mathrm{Al}^{3+}$ 等对其 苂光几乎没有影响.

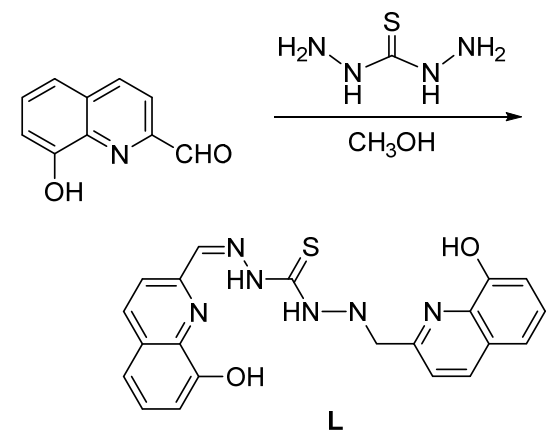

图 1 化合物 $\mathbf{L}$ 的合成

Figure 1 Synthetic route of compound $\mathbf{L}$

\section{1 结果与讨论}

\section{1 探针 $L$ 的设计、合成}

席夫碱是一类含有 $\mathrm{C}=\mathrm{N}$ 双键的化合物, 大多数能 够与金属离子螯合形成一种具有菼光特征的 “平面、刚 性和大共轭 $\pi$ 键” 的配合物. 尤其是当席夫碱与金属离 子配位后 $\mathrm{C}=\mathrm{N}$ 双键的构型会产生变化, 导致光谱产生 变化, 从而实现对特定离子或分子的选择性识别. 因此, 我们通过在硫代碳酰肼中引入 2 个 8 -差基喹啉菼光团得
到了化合物 $\mathbf{L}$. 其产率较高, 并通过 $\mathrm{IR},{ }^{1} \mathrm{H}$ NMR, ${ }^{13} \mathrm{C}$ NMR 谱和质谱以及元素分析表征了其结构.

\section{2 苂光和吸收光谱研究}

由于络合型苂光探针容易受到其他金属离子的影 响, 我们通过荧光光谱检测法做了探针 $\mathbf{L}$ 对 18 种常见 金属离子的选择性实验. 以 $296 \mathrm{~nm}$ 作为激发波长来检 测探针 $\mathbf{L}$ 对金属离子的选择性. 在 $\mathrm{CH}_{3} \mathrm{CN} / \mathrm{H}_{2} \mathrm{O}$ 混合溶 液 $(V: V=1: 2$, Tris 缓冲液 $50 \mathrm{mmol} / \mathrm{L}, \mathrm{pH}=7.3$ )中探针 $\mathbf{L}$ 的荧光发射光谱, 如图 2 所示. 探针 $\mathbf{L}$ 在 $296 \mathrm{~nm}$ 的激 发波长下表现出较弱的苂光. 向探针 $\mathbf{L}\left(3.33 \times 10^{-5}\right.$ $\mathrm{mol} / \mathrm{L})$ 中分别加入 18 种常见金属离子 $\left(3.33 \times 10^{-4}\right.$ $\mathrm{mol} / \mathrm{L})$, 如 $\mathrm{Li}^{+}, \mathrm{Na}^{+}, \mathrm{K}^{+}, \mathrm{Ca}^{2+}, \mathrm{Mg}^{2+}, \mathrm{Zn}^{2+}, \mathrm{Ag}^{+}, \mathrm{Pb}^{2+}$, $\mathrm{Hg}^{2+}, \mathrm{Fe}^{2+}, \mathrm{Cu}^{2+}, \mathrm{Mn}^{2+}, \mathrm{Ba}^{2+}, \mathrm{Co}^{2+}, \mathrm{Cd}^{2+}, \mathrm{Ni}^{2+}, \mathrm{Al}^{3+}$ 和 $\mathrm{Fe}^{3+}$, 其苂光强度几乎不发生变化. 然而, $\mathrm{Cr}^{3+}$ 的加入显 着增强了探针 $\mathbf{L}$ 在 $430 \mathrm{~nm}$ 处的苂光发射强度，这可能 是由于探针 $\mathbf{L}$ 分子结构中的 $\mathrm{N}-\mathrm{N}$ 键发生旋转, 同时 $\mathrm{C}-\mathrm{N}-\mathrm{N}$ 键角改变, 与 $\mathrm{C}=\mathrm{S}$ 键形成的空腔恰好与 $\mathrm{Cr}^{3+}$ 发生配位作用. 根据之前的文献报道, 具有酰胺、亚胺 基团的探针可以与金属离子配位，特别是与 $\mathrm{Cr}^{3+}$ 离子配 位 ${ }^{[18,19]}$. 这些结果表明, 我们设计的探针 $\mathbf{L}$ 具有选择性 检测 $\mathrm{Cr}^{3+}$ 的性能.

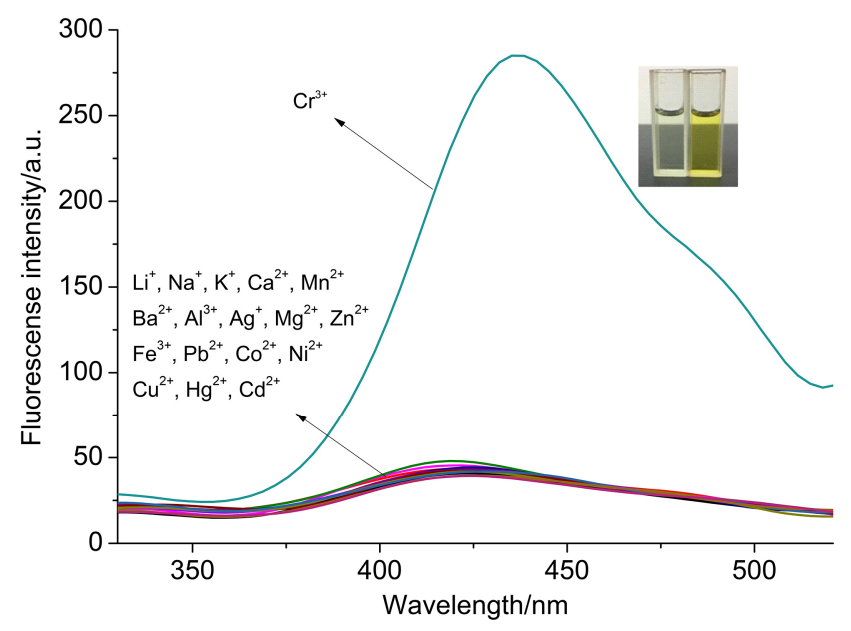

图 2 探针 $\mathbf{L}\left(3.33 \times 10^{-5} \mathrm{~mol} / \mathrm{L}\right)$ 在 $\mathrm{CH}_{3} \mathrm{CN} / \mathrm{H}_{2} \mathrm{O}(V: V=1: 2$, Tris buffer $50 \mathrm{mmol} / \mathrm{L}, \mathrm{pH}=7.3)$ 溶液中对不同金属离子 $(3.33 \times$ $10^{-4} \mathrm{~mol} / \mathrm{L}$ )的苂光响应(激发波长 $296 \mathrm{~nm}$ )

Figure 2 Fluorescence responses of probe $\mathbf{L}\left(3.33 \times 10^{-5} \mathrm{~mol} /\right.$ L) in $\mathrm{CH}_{3} \mathrm{CN} / \mathrm{H}_{2} \mathrm{O}(V: V=1: 2$, Tris buffer $50 \mathrm{mmol} / \mathrm{L}, \mathrm{pH}=$ 7.3) solution upon the addition of various metal ions $\left(3.33 \times 10^{-4}\right.$ $\mathrm{mol} / \mathrm{L})\left(\lambda_{\mathrm{ex}}=296 \mathrm{~nm}\right)$

为了更精确地理解探针 $\mathbf{L}$ 与 $\mathrm{Cr}^{3+}$ 的络合模式, 在 $\mathrm{CH}_{3} \mathrm{CN} / \mathrm{H}_{2} \mathrm{O}(V: V=1: 2$, Tris buffer $50 \mathrm{mmol} / \mathrm{L}, \mathrm{pH}=$ $7.3)$ 溶液中进行了苂光滴定实验. 如图 $3 \mathrm{a}$ 所示, 随着 $\mathrm{Cr}^{3+}$ 的浓度增加, 溶液的颜色从无色变为浅黄色, 探针 $\mathbf{L}$ 的苂光强度在 $430 \mathrm{~nm}$ 处成梯度升高. 当 $\mathrm{Cr}^{3+}$ 浓度增加 
到 2.05 倍后其苂光强度不再发生变化.
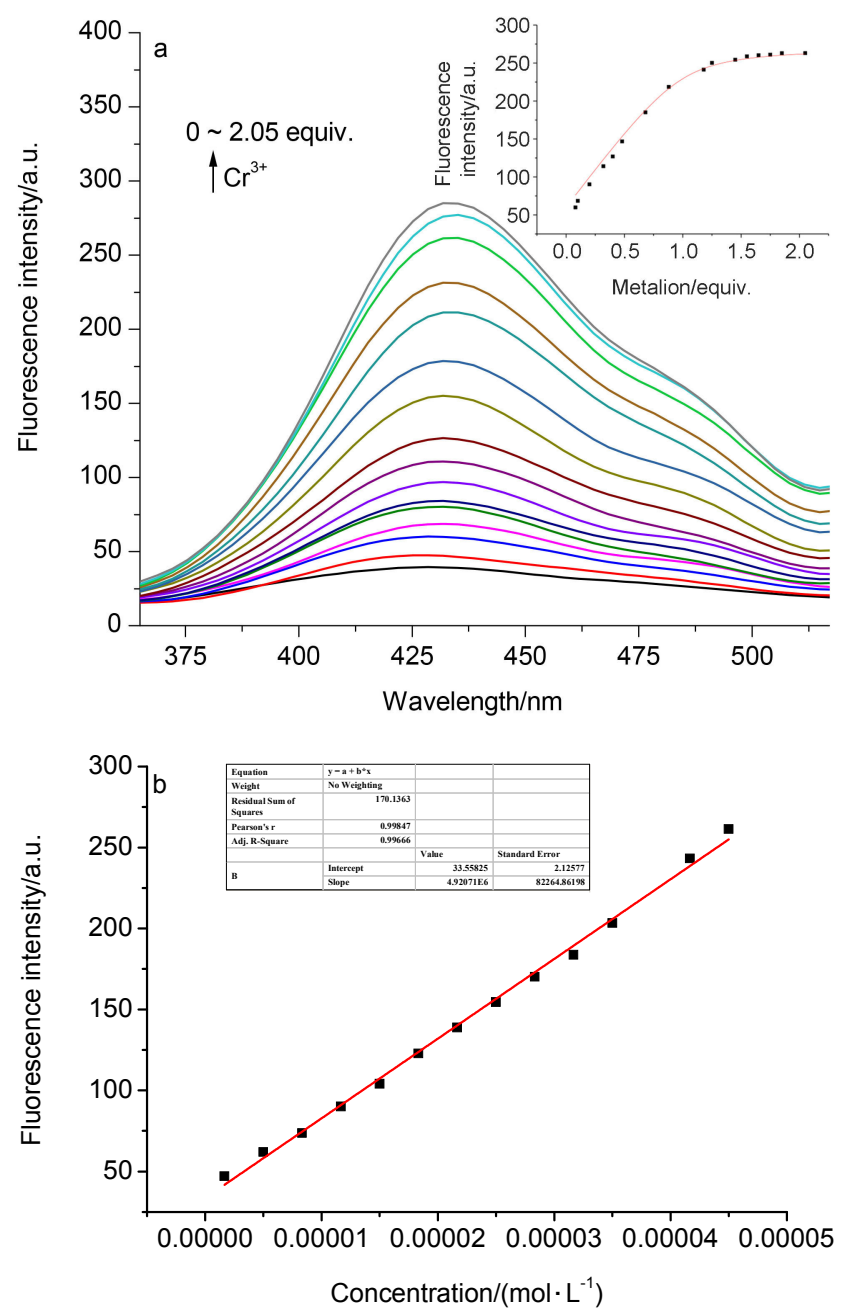

图 3 (a) 在 $\mathrm{CH}_{3} \mathrm{CN} / \mathrm{H}_{2} \mathrm{O}(V: V=1: 2$, Tris 缓冲液 $50 \mathrm{mmol} / \mathrm{L}$, $\mathrm{pH}=7.3)$ 溶液中滴加 $0 \sim 2.05$ equiv. $\mathrm{Cr}^{3+}$ 时探针 $\mathbf{L}\left(3.33 \times 10^{-5}\right.$ $\mathrm{mol} / \mathrm{L}$ ) 的荧光发射光谱和(b)探针 $\mathbf{L}$ 在 $430 \mathrm{~nm}$ 处荧光强度与 $\mathrm{Cr}^{3+}$ 的线性关系

Figure 3 (a) Fluorescence emission spectra of probe $\mathbf{L}(3.33 \times$ $\left.10^{-5} \mathrm{~mol} / \mathrm{L}\right)$ in $\mathrm{CH}_{3} \mathrm{CN} / \mathrm{H}_{2} \mathrm{O}(V: V=1: 2$, Tris buffer 50 $\mathrm{mmol} / \mathrm{L}, \mathrm{pH}=7.3$ ) upon the addition of $\mathrm{Cr}^{3+}$, and (b) linear relationship of fluorescence intensity at $430 \mathrm{~nm}$ of probe $\mathbf{L}$ as a function of $\mathrm{Cr}^{3+}$

(a) Inset: Fluorescence intensity of probe $\mathbf{L}$ as the concentration $\mathrm{Cf}^{3+}$ increase, solid line is a nonlinear fitting curve, $R^{2}=0.99125$. (b) $(3 \mathrm{~S} / \rho)=$ $2.85 \times 10^{-7}$

通过绘制非线性拟合曲线(如图 3a 插图), 计算出结 合常数 $K_{\mathrm{a}}=1.00 \times 10^{5} \mathrm{~L} / \mathrm{mol}$, 其相关系数 $\left(R^{2}\right)$ 大于 0.98 , 表明探针 $\mathbf{L}$ 与 $\mathrm{Cr}^{3+}$ 形成 $1: 1$ 复合物. 同时, Job 曲线和 质谱检测也显示出探针 $\mathbf{L}$ 与 $\mathrm{Cr}^{3+}$ 是 $1: 1$ 络合, 质谱检 测发现探针 $\mathbf{L}$ 与 $\mathrm{Cr}^{3+}$ 络合后的离子峰 $m / z$ 为 466.32 , 与 理论值 466.34 几乎一致. 又根据苂光滴定实验进一步计 算出 $\mathrm{Cr}^{3+}$ 离子的检出限为 $2.85 \times 10^{-7} \mathrm{~mol} / \mathrm{L}$ (图 3b). 其 检出限低于环境保护局和世界卫生组织(WHO) 设定的 饮用水中 $\mathrm{Cr}^{3+}$ 离子 $(20 \mu \mathrm{mol} / \mathrm{L})$ 的最大允许值 ${ }^{[22]}$. 这些结
果表明，探针 $\mathbf{L}$ 具有较高灵敏度，可以用于检测水中的 $\mathrm{Cr}^{3+}$ 的浓度.

为了研究其他金属离子对 $\mathrm{Cr}^{3+}$ 检测的影响, 我们进 行了干扰性实验. 实验结果显示, $\mathrm{Cr}^{3+}$ 离子 $\left(6.66 \times 10^{-4}\right.$ $\mathrm{mol} / \mathrm{L})$ 与其他金属离子 $\left(6.66 \times 10^{-4} \mathrm{~mol} / \mathrm{L}\right)$ 混合物引起的 探针 $\mathbf{L}\left(3.33 \times 10^{-5} \mathrm{~mol} / \mathrm{L}\right)$ 苂光增强与单独使用 $\mathrm{Cr}^{3+}$ 引 起的苂光增强相似(图 4). 这些金属离子的存在不会干 扰探针 $\mathbf{L}$ 对 $\mathrm{Cr}^{3+}$ 离子的检测，表明探针 $\mathbf{L}$ 是具有高度选 择性的 $\mathrm{Cr}^{3+}$ 离子苂光探针 ${ }^{[21]}$. 其次, $\mathrm{pH}$ 对探针 $\mathbf{L}$ 苂光强 度的影响实验表明，探针 $\mathbf{L}$ 可以用作在弱碱性环境或生 物条件下检测有效的 $\mathrm{Cr}^{3+}$.

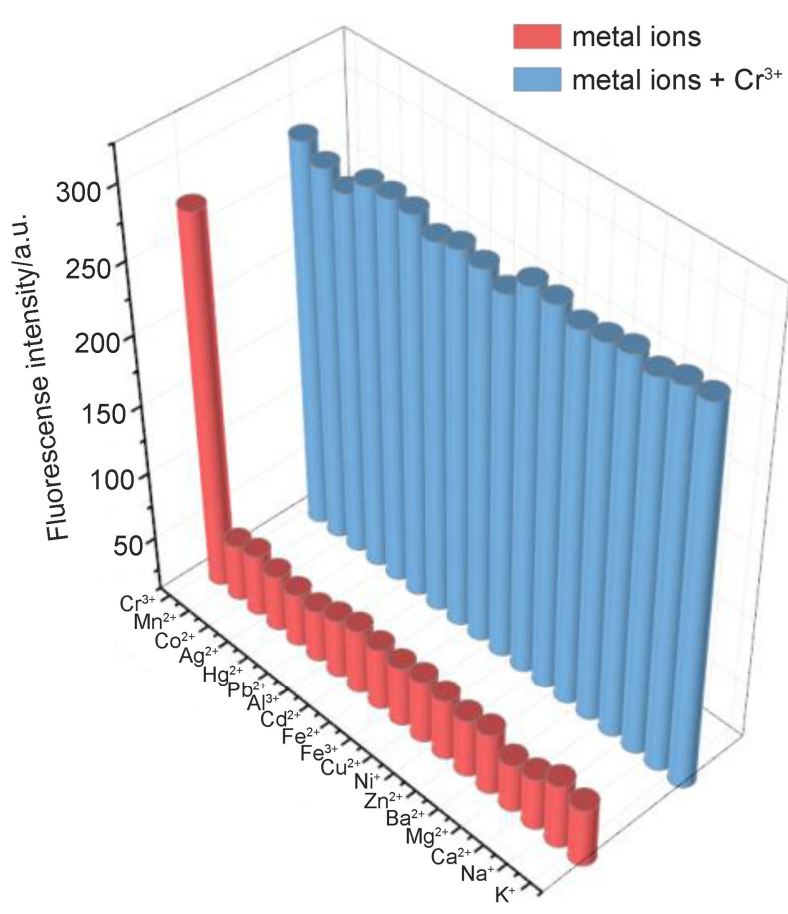

图 4 在 $\mathrm{CH}_{3} \mathrm{CN} / \mathrm{H}_{2} \mathrm{O}(V: V=1: 2$, Tris 缓冲液 $50 \mathrm{mmol} / \mathrm{L}$, $\mathrm{pH}=7.3)$ 溶液中加入各种金属离子 $\left(6.66 \times 10^{-4} \mathrm{~mol} / \mathrm{L}\right)$ 后 $\mathbf{L}$ $\left(3.33 \times 10^{-4} \mathrm{~mol} / \mathrm{L}\right)$ 的荧光强度

Figure 4 Fluorescence intensity of $\mathbf{L}\left(3.33 \times 10^{-4} \mathrm{~mol} / \mathrm{L}\right)$ upon addition of various metal ions $\left(6.66 \times 10^{-4} \mathrm{~mol} / \mathrm{L}\right)$ in $\mathrm{CH}_{3} \mathrm{CN} / \mathrm{H}_{2} \mathrm{O}(V: V=1: 2$, Tris buffer $50 \mathrm{mmol} / \mathrm{L}, \mathrm{pH}=7.3)$ solution

The red bars: $\mathbf{L}$ with competing ion, blue bars: $\mathbf{L}$ with competing ion and $\mathrm{Cr}^{3+}$

\section{3 络合模式研究}

为了研究探针 $\mathbf{L}$ 对 $\mathrm{Cr}^{3+}$ 的结合模式, 我们进行了 UV-Vis 滴定实验. 未加入 $\mathrm{Cr}^{3+}$ 时探针 $\mathbf{L}$ 在 260,310 和 $350 \mathrm{~nm}$ 处的三个吸收峰为 $\pi-\pi^{*}$ 电荷转移 ${ }^{[24]}$, 随着 $\mathrm{Cr}^{3+}$ 浓度的增加, 探针 $\mathbf{L}$ 在 $260 \mathrm{~nm}$ 的吸收峰逐渐减弱, 在 310 和 $350 \mathrm{~nm}$ 处的吸收峰增加, 231 和 $300,334 \mathrm{~nm}$ 处的 三个等吸收点的存在和继续增加 $\mathrm{Cr}^{3+}$ 后探针 $\mathbf{L}$ 的 UV-Vis 不再发生变化表明探针 $\mathbf{L}$ 与 $\mathrm{Cr}^{3+}$ 形成了稳定的 
络合物. IR 实验也对比了探针 $\mathbf{L}$ 与其 $\mathrm{Cr}^{3+}$ 络合物的光谱 变化, 探针 $\mathbf{L}$ 在 1537 和 $1499 \mathrm{~nm}$ 处的 $\mathrm{N}-\mathrm{C}=\mathrm{S}$ 键的吸 收峰, 较探针 $\mathbf{L}$ 的相同位置吸收峰有一定的减弱, 这也 表明 $\mathrm{C}=\mathrm{S}$ 键参与了形成络合物.

为了更好的验证探针 $\mathbf{L}$ 与 $\mathrm{Cr}^{3+}$ 在溶液中的配位行 为, ${ }^{1} \mathrm{H}$ NMR (图 5) 实验表明, 在 $0.001 \mathrm{~mol} / \mathrm{L}$ 的探针 $\mathbf{L}$ 的 DMSO- $d_{6}$ 中, 加入 1.0 equiv. $\mathrm{Cr}^{3+}$ 后, 探针 $\mathbf{L}$ 在 $\delta 10.10$ 处的羟基的信号强度明显减弱, 这表明在络合过程中 $\mathrm{OH}$ 基团参与了络合. 探针 $\mathbf{L}$ 的 $\mathrm{NH}(\delta 12.78$ 和 12.34)与 芳香区信号 $(\delta 8.58,8.53,7.66$ 和 7.33)向高场移动. 这些 结果表明, 探针 $\mathbf{L}$ 与 $\mathrm{Cr}^{3+}$ 的结合是通过与席夫碱的氮、 喹啉的氮、羟基氧和硫代碳酰肼的硫的螯合反应形成刚 性体系.

Probe $\mathrm{L}+1.5$ equiv. $\mathrm{Cr}^{3+}$

图 5 探针 $\mathbf{L}(0.001 \mathrm{~mol})$ 和 $\mathbf{L} / \mathrm{Cr}\left(\mathrm{NO}_{3}\right)_{3}$ 在 DMSO- $d_{6}$ 中的氢谱 $\left(0 \sim 1.5\right.$ equiv. $\left.\mathrm{Cr}^{3+}\right)$

Figure $5{ }^{1} \mathrm{H}$ NMR spectra of probe $\mathbf{L}(0.001 \mathrm{~mol})$ with $\mathrm{Cr}\left(\mathrm{NO}_{3}\right)_{3}$ in DMSO- $d_{6}\left(0 \sim 1.5\right.$ equiv. $\left.\mathrm{Cr}^{3+}\right)$

\subsection{DFT 计算}

最后, 为了更深入地了解探针 $\mathbf{L}$ 与 $\mathrm{Cr}^{3+}$ 的结合机 制. 我们通过密度泛函理论(DFT)计算成功优化了探针 $\mathbf{L}$ 的结构及其与 $\mathrm{Cr}^{3+}$ 络合物的结构(图 6). 计算过程中 C, H, O, N, S 元素使用 B3LYP/6-31G 基组, Cr 元素使用 LANL2DZ 噟势基组. 我们都知道最高占据分子轨道 (HOMO)和最低未占分子轨道(LUMO)被称为前沿分子 轨道(FMO), 它们被广泛用于更好地理解化学传感器及 其复合物的光谱性质. 通常情况下, 光谱性质与 HOMO-LUMO 间隙和电子分布密切相关. 如图 6 所示, 与探针 $\mathbf{L}$ 的能隙值 $\Delta E=2.6003 \mathrm{eV}$ 相比, $\mathbf{L}-\mathrm{Cr}^{3+}$ 络合物 的能隙值 $\Delta E=1.4728 \mathrm{eV}$, 降低了 $1.1275 \mathrm{eV}$, 说明 $\mathrm{Cr}^{3+}$ 配位后轨道间相互作用使得配体与金属之间产生电荷 转移效应, 整个分子体系的能量降低, 分子趋于更加稳 定, 探针 $\mathbf{L}$ 向 $\mathbf{L}-\mathrm{Cr}^{3+}$ 络合物的转化变得更加容易 ${ }^{[23]}$. 根 据优化后 $\mathbf{L}-\mathrm{Cr}^{3+}$ 络合物的结构可知, $\mathrm{Cr}$ 原子到硫代碳酰 肼的 $\mathrm{S}$ 原子、 $\mathrm{N}$ 原子和喹啉 $\mathrm{N}$ 原子、羟基 $\mathrm{O}$ 原子的距 离分别是 $2.4,1.9$ 和 1.9, $2.1 \AA$, 这表明羟基 $\mathrm{O}$ 原子和其 中一个喹啉的 $\mathrm{N}$ 原子与硫代碳酰肼的 $\mathrm{S}, \mathrm{N}$ 原子之间形 成的空间结构恰好可以提供一个适当的螯合中心来络 合 $\mathrm{Cr}^{3+}$. 此外, 该图也揭示了从 HOMO 向 LUMO 转变
时电子密度分布的显着变化. 探针 $\mathbf{L}$ 的 HOMO 轨道的 $\pi$ 电子主要分布在硫代碳酰肼长链上，而 LUMO 轨道则 分布在喹啉环的一侧上. 对于络合物 $\mathbf{L}-\mathrm{Cr}^{3+}, \mathrm{HOMO}$ 轨 道和 LUMO 轨道的 $\pi$ 电子主要位于喹啉环的一侧. 我们 都知道，喹啉环是 2 个荧光团，它们之间通过硫代碳酰 肼长链进行桥接，当被激发时，分子内的电荷会在其中 移动. 加入 $\mathrm{Cr}^{3+}$ 后, 喹啉 $\mathrm{N}$ 的孤对电子与 $\mathrm{Cr}^{3+}$ 离子紧紧 纠缠在一起. 因此, 改变了整个分子系统的推拉电子能 力, 并且 $\pi$ 电子结构重新分布. 这就导致了络合时苂光 发射强度增加，光谱向长波方向移动的现象. 说明探针 $\mathbf{L}$ 对 $\mathrm{Cr}^{3+}$ 络合是通过 ICT 过程实现的 ${ }^{[25]}$.

\section{5 细胞成像及形态学应用研究}

为了进一步拓展探针 $\mathbf{L}$ 在生物系统中的应用, 将 PC-12 细胞在 $37{ }^{\circ} \mathrm{C}$ 下捊育 $30 \mathrm{~min}$ 后在 Dulbecco's modified Eagle's medium 培养基进行了细胞成像实验 ${ }^{[26]}$. 探针 $\mathbf{L}$ 的浓度在 $0 \sim 20 \mu \mathrm{mol} / \mathrm{L}$ 范围内存活率能达到 $85 \%$ 以上. 如图 7 所示, 用探针 $\mathbf{L}(20 \mu \mathrm{mol} / \mathrm{L})$ 处理 PC-12 细胞, 在培养基中孵育 $30 \mathrm{~min}$ 后, 在倒置苂光显微镜下 只能观察到明场细胞的完整形态(图 7a), 观察不到细胞 的荧光(图 7b). 此外，当 PC-12 细胞与探针 $\mathbf{L}(20$ $\mu \mathrm{mol} / \mathrm{L}) \mathrm{Cr}^{3+}(20 \mu \mathrm{mol} / \mathrm{L})$ 在培养基共同睬育 $30 \mathrm{~min}$ 后, 可以观察到明显的蓝色荧光(图 7d), 表明探针 $\mathbf{L}$ 和 $\mathrm{Cr}^{3+}$ 可以进入细胞内, 并形成络合物. 同时在明亮的视野中, 细胞的形态是完整的(图 7a 和 7c), 表明探针 $\mathbf{L}$ 可用于检 测活细胞中的 $\mathrm{Cr}^{3+[27,28]}$.

探针 $\mathbf{L}$ 及其铬(III)配合物的形貌特征如图 8 所示. 只有探针 $\mathbf{L}$ 存在时，其形貌是交联在一起形成的枝条状 结构, 引入铬(III)后, 枝条型结构被破坏, 形成块状和 胶束型结构. 明显的形态学变化表明, 铬(III)对探针 $\mathbf{L}$ 的协调作用在一定程度上对探针 $\mathbf{L}$ 在材料方面的性能 有一定的影响.

\section{2 结论}

设计并合成了一种新型席夫碱苂光探针 $\mathbf{L}$, 在其他 金属离子存在下, 探针 $\mathbf{L}$ 对 $\mathrm{Cr}^{3+}$ 具有显着苂光增强作 用, 溶液的颜色由无色变为浅黄色. 荧光滴定和 Job 曲 线等研究结果表明, 探针 $\mathbf{L}$ 与 $\mathrm{Cr}^{3+}$ 形成 $1: 1$ 络合物. 结 合常数 $K_{\mathrm{a}}$ 为 $1.00 \times 10^{5} \mathrm{~L} / \mathrm{mol}$, 检测限 $(\mathrm{LOD})$ 为 $2.85 \times$ $10^{-7} \mathrm{~mol} / \mathrm{L}$, 探针 $\mathbf{L}$ 和 $\mathrm{Cr}^{3+}$ 的络合为 ICT 机制. 通过 DFT 计算优化了探针 $\mathbf{L}$ 及 $\mathbf{L}-\mathrm{Cr}^{3+}$ 的合理结构. 活细胞成像实 验研究结果表明, 探针 $\mathbf{L}$ 对活细胞具有低毒性, 对细胞 膜具有高渗透性，可以用于检测活细胞内的 $\mathrm{Cr}^{3+}$. 因此， 该探针具有潜在地应用于检测自然环境或生物体内的 $\mathrm{Cr}^{3+}$ 的性能. 


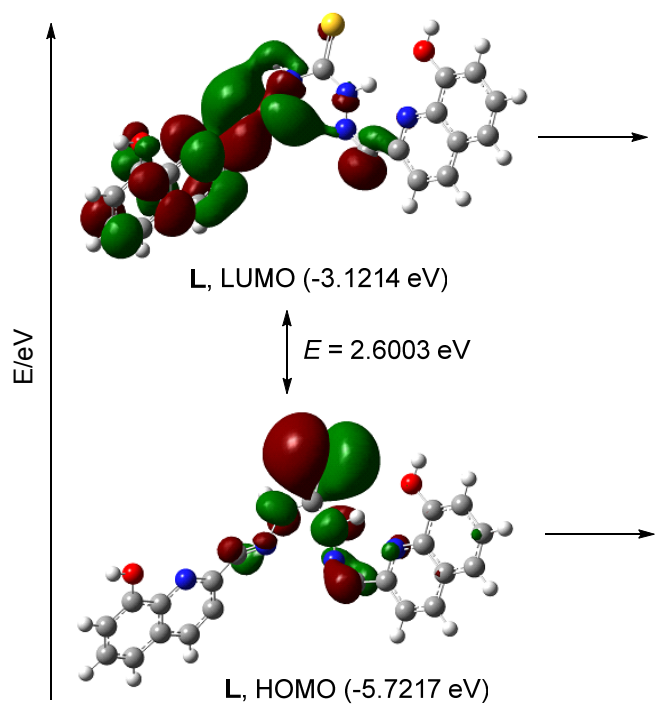

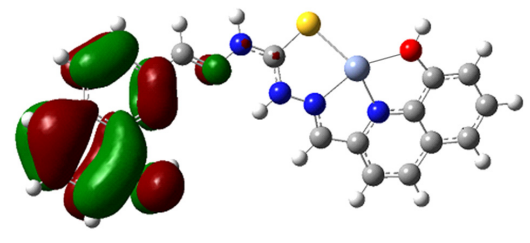

$\mathrm{L}+\mathrm{Cr}^{3+}, \mathrm{LUMO}(-12.9050 \mathrm{eV})$ $\Uparrow=1.4728 \mathrm{eV}$

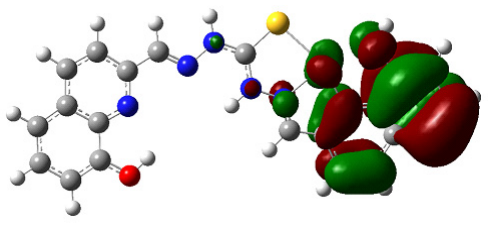

$\mathbf{L}+\mathrm{Cr}^{3+}, \mathrm{HOMO}(-14.3778 \mathrm{eV})$

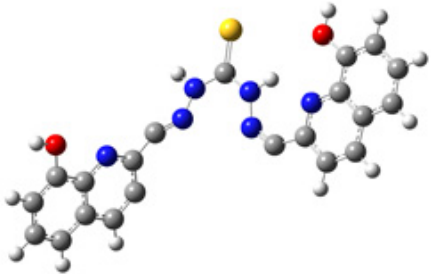

$\mathbf{L}$

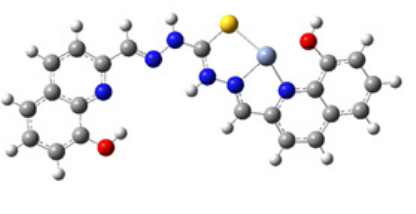

$\mathbf{L}+\mathrm{Cr}^{3+}$

图 6 探针 $\mathbf{L}$ 和 $\mathbf{L}-\mathrm{Cr}^{3+}$ 的前线分子轨道密度分布图和能隙

Figure 6 Electron density maps of the frontier molecular orbital structures and band gap energies of probe $\mathbf{L}$ and $\mathbf{L}-\mathrm{Cr}^{3+}$

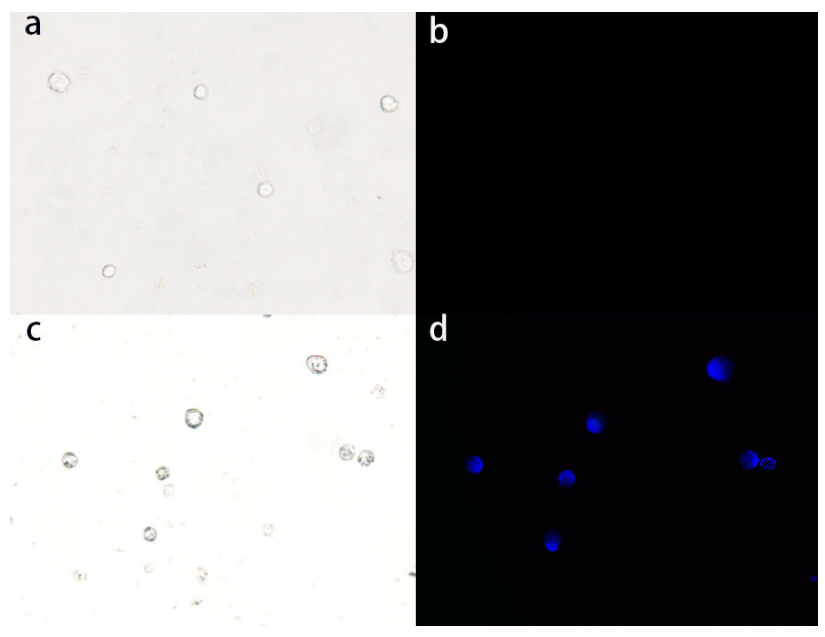

图 $7 \mathrm{HeLa}$ 细胞的明场图像和苂光图像

Figure 7 Bright field image and fluorescence image of HeLa cells

Bright field image HeLa cells incubated with $\mathbf{L}(20 \mu \mathrm{mol})$ for 30 min at $35{ }^{\circ} \mathrm{C}$. (b) Fluorescence image of HeLa cells incubated with $\mathbf{L}(20 \mu \mathrm{mol} /$ L). (c) Bright field image of $\mathbf{L}(20 \mu \mathrm{mol} / \mathrm{L})$ treated HeLa cells again incubated with $\mathrm{Cr}^{3+}(20 \mu \mathrm{mol})$. (d) Fluorescence image of $\mathbf{L}(20 \mu \mathrm{mol} / \mathrm{L})$ treated $\mathrm{HeLa}$ cells and with $\mathrm{Cr}^{3+}(20 \mu \mathrm{mol} / \mathrm{L})$

\section{3 实验部分}

\section{1 仪器与试剂}

熔点用 MEL-TEMP 型熔点仪测定; 苂光光谱使用 F-7000 型荧光光谱仪; 核磁共振氢谱、碳谱使用 BrukerAV-400 型核磁共振波谱仪测定; 质谱用 Esquier 3000 型 LC-MS 质谱仪测定; 在 Nicolet6710-FT-IR 分光 光度计上记录; 元素分析使用德国 Elementar Vario EL cube 元素分析仪; SEM 图像使用蔡司 GEMINI-SEM 500 扫描电子显微镜记录. 实验所用试剂均为市售分析纯试
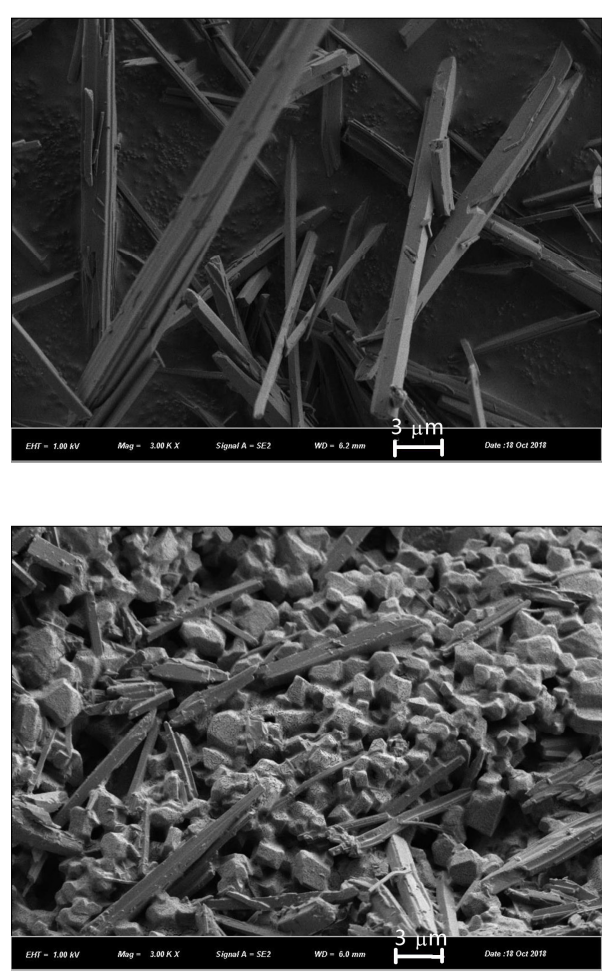

图 $8 \mathrm{~L}$ 和复合物 $\mathrm{L}_{-} \mathrm{Cr}^{3+}$ 的 $\mathrm{SEM}$ 图像

Figure 8 SEM image of $\mathbf{L}$ and their complex with $\mathrm{Cr}^{3+}$

剂, 所有溶剂使用前均使用标准方法纯化.

\section{2 实验方法}

\subsection{1 二-(8-羟基喹啉-2-基)-硫代碳酰胖的合成}

将 $0.50 \mathrm{~g}(2.80 \mathrm{mmol}) 8$-手基喹啉酫置于 $50 \mathrm{~mL}$ 圆 底烧瓶中, 加入 $10 \mathrm{~mL}$ 甲醇完全溶解. 用恒压漏斗将 10 $\mathrm{mL}$ 水 $+10 \mathrm{~mL}$ 甲醇完全溶解 $0.15 \mathrm{~g}(1.40 \mathrm{mmol})$ 的硫代 碳酰肼溶液滴入圆底烧瓶中, 在 $65{ }^{\circ} \mathrm{C}$ 回流下反应 $6 \mathrm{~h}$, 
析出浅黄色沉淀. 滤出沉淀经甲醇反复洗涤和真空干燥 后收集产物 $1.13 \mathrm{~g}$, 产率 96\%. m.p. 264.1 265.6 ${ }^{\circ} \mathrm{C} ;{ }^{1} \mathrm{H}$ NMR (DMSO- $\left.d_{6}\right) \delta: 12.78(\mathrm{~s}, 1 \mathrm{H}), 12.34(\mathrm{~s}, 1 \mathrm{H}), 10.10$ (s, 2H), $8.58(\mathrm{~s}, 2 \mathrm{H}), 8.53(\mathrm{~s}, 2 \mathrm{H}), 7.70 \sim 7.62(\mathrm{~m}, 6 \mathrm{H}), 7.33$ $(\mathrm{s}, 2 \mathrm{H}) ;{ }^{13} \mathrm{C}$ NMR (DMSO- $\left.d_{6}\right) \delta: 176.09,153.96,151.71$, 138.53, 137.03, 129.37, 128.84, 118.33, 112.67; IR (KBr) v: 3483, 3357, 2982, $1537 \mathrm{~cm}^{-1}$; ESI-MS m/z: 417.24 $\left([\mathrm{M}+\mathrm{H}]^{+}\right)$. Anal. calcd for $\mathrm{C}_{21} \mathrm{H}_{16} \mathrm{~N}_{6} \mathrm{O}_{2} \mathrm{~S}: \mathrm{C} 60.57$, H 3.87, N 20.18; found C 60.51, H 3.91, N 20.13.

\section{2 .2 荧光光谱测定}

制备 $\mathrm{Na}^{+}, \mathrm{K}^{+}, \mathrm{Ba}^{2+}, \mathrm{Ca}^{2+}, \mathrm{Mg}^{2+}, \mathrm{Ag}^{+}, \mathrm{Pb}^{2+}, \mathrm{Hg}^{2+}$, $\mathrm{Co}^{2+}, \mathrm{Cu}^{2+}, \mathrm{Zn}^{2+}, \mathrm{Cr}^{3+}, \mathrm{Cd}^{2+}, \mathrm{Fe}^{3+}, \mathrm{Ni}^{2+}, \mathrm{Zn}^{2+}, \mathrm{Al}^{3+}$ 的硝 酸盐储备液. 将化合物 $\mathbf{L}$ 溶解在 $V\left(\mathrm{CH}_{3} \mathrm{CN}\right) / V\left(\mathrm{H}_{2} \mathrm{O}\right)=$ $1 / 2,50 \mathrm{mmol} / \mathrm{L}$ Tris 缓冲液, $\mathrm{pH}=7.3$ )中, 再将 $3 \mathrm{~mL}$ 探针 原液置于 $1 \mathrm{~cm}$ 石英比色典, 然后使用微量移液枪加入 $10 \mu \mathrm{L}$ 各金属离子原液, 制备试验溶液. 荧光激发波长 为 $296 \mathrm{~nm}$ (狭缝宽度为 $5 \mathrm{~nm}$ ).

\subsection{3 理论计算}

使用 Gaussian 09 软件进行量子化学计算. 用于获 得探针的能量最小优化结构. 通过密度泛函理论(DFT) 以 $\mathrm{B} 3 \mathrm{LYP} / 6-31 \mathrm{G}^{* *}$ 基组进行了计算 ${ }^{[29]}$. 通过检查振动频 率的真实最小值, 没有发现虚频. 从探针 $\mathbf{L}$ 的优化结构 获得最高占据分子轨道(HOMO)和最低未占分子轨道 (LUMO)的电子分布图.

\subsection{4 细胞成像测试}

HeLa 细胞在 Dulbecco's modified Eagle's medium (DMEM)培养基中生长, 补充 10\%牛血清和 $1 \%$ 青霉素链霉素, 在 $5 \% \mathrm{CO}_{2}$ 和 $95 \%$ 空气的湿润气氛下于 $37{ }^{\circ} \mathrm{C}$ 温育 $24 \mathrm{~h}^{[30]}$. 通过倒置苂光显微镜, 将细胞接种在培养 皿上，用于苂光显微镜成像.

\subsubsection{SEM 成像实验}

使用具有 $1 \mathrm{kV}$ 加速电压的 ZEISS GEMINI-SEM 500 扫描电子显微镜 $(\mathrm{SEM})$ 研究探针 $\mathbf{L}$ 的微观形态. 将 溶解了探针 $\mathbf{L}(0.1 \mathrm{~mol} / \mathrm{L})$ 和 $\mathbf{L}+\mathrm{Cr}^{3+}(0.1 \mathrm{~mol} / \mathrm{L})$ 的乙醇 悬浮液分别置于小载玻片上, 然后在真空下蒸发溶剂来 制备用于 SEM 研究的样品 ${ }^{[31]}$.

辅助材料(Supporting Information) 合成的新化合物
的核磁氢谱、碳谱，质谱以及探针测试的紫外光谱，红 外光谱和 $\mathrm{pH}$ 实验, JOB 曲线, 细胞毒性等数据. 这些材 料可以免费从本刊网站(http://sioc-journal.cn/)上下载.

\section{References}

[1] Vincent, J. B. Proc. Nutr. Soc. 2004, 63, 41.

[2] Filik, H.; Dondurmacioglu, F. J. Anal. Chem. 2009, 64, 455.

[3] Wang, Y. T. J. Ind. Microbiol. Biotechnol 1995, 14, 159.

[4] Filik, H.; Dondurmacioglu, F. J. Anal. Chem. 2009, 64, 455.

[5] Chalmardia, G. B.; Tajbakhsha, M. Tetrahedron 2018, 18, 40.

[6] Gou, C.; Qin, S. H.; Wang, Y.; Liu, X. Y. Inorg. Chem. Commun. 2011, 14, 1622.

[7] Azadbakht, R.; Keypour, H. Spectrochim. Acta, Part A 2012, 85, 293.

[8] Vincent, J, B. Nutr. Rev. 2000, 58, 67.

[9] Anderson, R. A. Regul. Toxicol. Pharmacol. 1997, 26, 35.

[10] Filik, H.; Dondurmacioglu, F. J. Anal. Chem. 2009, 64, 455.

[11] Gómez, V.; Callao, M. P. TrAC, Trends Anal. Chem. 2006, 25, 1006.

[12] Lu, J. S.; Tian, J. Y.; Wu, H. Chin. J. Anal. Chem. 2009, 37, 99.

[13] Xu, K. X.; Kong, H. J.; Li, Q.; Song, P.; Dai, Y. P.; Li, Y. Spectrochim. Acta, Part A 2015, 137, 957.

[14] Kamakura, N.; Inui, T.; Kitano, M.; Nakamura, T. Spectrochim. Acta, Part B 2014, 93, 28.

[15] Li, M.; Zhang, D.; Liu, Y.; Ding, P. J. Fluorescence 2014, 24, 119.

[16] Noorbasha, N. M.; Jiangb, S. J. Talanta 2009, 80, 173.

[17] Zhang, N.; Suleiman, J. S.; He, M. Talanta 2008, 75, 536.

[18] Aydan, F. A.; Soylak, M. J. Hazard. Mater. 2010, 173, 669.

[19] Xie, X.; Tang, F.; Shangguan, X.; Che, S.; Niu J.; Xiao, Y.; Wang, X.; Tang, B. Chem. Commun. 2017, 53, 6520.

[20] Dai, Y. P.; Fu, J. X.; Yao, K.; Song, Q. Q.; Xu, K. X. Spectrochim. Acta, Part A 2018, 192, 257.

[21] Dolaia, M.; Sahab, U.; Dasc, A. K.; Kumarb, G. S. Anal. Methods-UK 2018, 10, 4063.

[22] Liu, X. Y.; Wang, P.; Fu, J. X.; Yao, K.; Xue, K.; Xu, K. X. J. Lumin. 2017, 186, 16.

[23] Brewer, T. F.; Chang, C. J. J. Am. Chem. Soc. 2015, 137, 10886.

[24] Keck, J.; Kramer, H. E. A.; Port, H.; Hirsch, T.; Fischer, P.; Rytz, G. J. Phys. Chem. 1996, 100, 14468.

[25] Hou, S. H.; Qu, Z. G.; Zhong, K. H.; Bian, Y. J.; Tang, L. J. Chin. J. Org. Chem. 2016, 36, 768 (in Chinese). (侯淑华, 曲忠国, 钟克利, 边延江, 汤立军, 有机化学, 2016, 36, 768.)

[26] Yao, K.; Fu, J. X.; Chang, Y. X.; Li, B.; Li, Y.; Xu, K. X. Spectrochim. Acta, Part A 2018, 205, 410.

[27] Zhang, P.; Wang, H.; Zhang, D.; Zeng, X.; Zeng, R.; Xiao, L.; Tao, H.; Long, Y.; Yi, P.; Chen, J. Sens. Actuators, B 2018, 255, 2223.

[28] Fu, Y. J.; Yao, H. W.; Zhu, X. Y.; Guo, X. F.; Wang, H. Anal. Chim. Acta 2017, 994, 1.

[29] Dai, Y. P.; Liu, X. Y.; Wang, P.; Fu, J. X.; Yao, K.; Xu, K. X. RSC Adv. 2016, 6, 99933.

[30] Wang, P.; Fu, J. X.; Yao, K. Chang, Y. X.; Xu, K. X. Sens. Actuators, $B$ 2018, 273, 1070.

[31] Samir, M.; Milan, S.; Debasish, D.; Prativa, M.; Gobinda, P.; Sahoo, A. Sens. Actuators, B 2017, 248, 223. 